\title{
PESQUISA CIENTÍFICA NA ENGENHARIA CIVIL EAD: RELATO DE EXPERIÊNCIA
}

\author{
PARAUAPEBAS/PA MAIO/2018
}

\author{
Amanda Gil Cardoso de Lima \\ - UNIUBE - amanda.lima@uniube.br \\ Tiago Zanquêta de Souza - UNIUBE - tiago.zanqueta@uniube.br
}

Tipo: Relato de Experiência Inovadora (EI)

Categoria: Conteúdos e Habilidades

Setor Educacional: EDUCAÇÃO SUPERIOR

\begin{abstract}
RESUMO
O curso de Engenharia Civil da Universidade de Uberaba se propõe a formar profissionais capazes de atuar em diversas áreas de abrangência dentre elas: hidráulica e recursos hídricos; construção civil; geotecnia; estruturas e transportes. A recessão econômica atual e a redução dos investimentos em obras públicas, exige dos profissionais da área constante adaptação, além de uma atuação multifacetada, o que implica aquisição de inúmeras habilidades e competências. Desse modo, tal adaptação ao mercado instável, permite expandir seu conhecimento para além da Construção Civil. Tendo em vista a necessidade desse diferencial profissional, um grupo de alunos do curso de Engenharia Civil EAD, do Polo de Parauapebas/Pa, da Universidade de Uberaba, buscou com orientação da tutoria pertinente, ampliar seus conhecimentos na área de Materiais da Construção Civil e Sustentabilidade. Para isso, realizaram uma pesquisa com uso de escória de siderúrgica, material que seria descartado, dando a ele novo uso e avaliando seus possíveis benefícios para a Dosagem de Concretos. O grupo submeteu o resumo da pesquisa ao IBRACON - Instituto Brasileiro do Concreto, renomado congresso de caráter nacional que aborda as novas tecnologias acerca da produção de concreto e seus usos, e lograram êxito para publicação. Este artigo, então, tem como objetivo relatar a experiência da produção científica de alunos de modalidade de ensino à distância, vinculados ao curso de Engenharia Civil, para reforçar a importância do trabalho dos professores tutores junto a esses estudantes, de modo a estimulá-los à busca de novos conhecimentos e ao investimento na produção acadêmica.
\end{abstract}

Palavras-chave: EAD; pesquisa científica; engenharia civil

\section{AGRADECIMENTOS}

AGRADEÇO AOS ALUNOS PAULA, FELIPE E AFONSO, QUE ABRAÇARAM O DESAFIO E PROPICIARAM A REALIZAÇÃO DESTE ESTUDO, E ÀS INSTITUIÇÕES UNIVERSIDADE DE UBERABA E ESCOLA TÉCNICA VALE DOS CARAJÁS PELO SUPORTE. 


\section{Contexto educacional e profissional de Parauapebas}

O polo de Parauapebas está situado em uma região com atividades industriais, onde se localizam diversas siderúrgicas e empresas dos ramos da mineração, geotecnia e construção pesada. Grande parte da população atua nessas áreas, o que torna o cenário local altamente competitivo, tendo em vista que a cidade atrai trabalhadores de todo país em busca de novas oportunidades nas diferentes áreas das Engenharias. Dessa forma, os estudantes buscam o desenvolvimento de habilidades além daquelas desenvolvidas durante o período acadêmico, visando diferenciar-se dos demais profissionais da área.

$\mathrm{Na}$ cidade existe a oferta do curso de Engenharia Civil, na modalidade presencial, por uma Universidade Federal, porém, em unidades modulares, com a formação de apenas uma turma a cada período, ou seja, somente a cada cinco anos são abertas vagas para uma (única) nova turma, vagas essas que não suprem a necessidade profissional da região. O Polo EAD Uniube chegou a Parauapebas em 2013, como a primeira universidade particular a ofertar diferentes Engenharias, atendendo essa demanda e formando profissionais de qualidade na região. Com o primeiro vestibular foram formadas 10 turmas, sendo até hoje, a única Universidade a oferecer Engenharia na modalidade EAD da região, licenciada no CREA - Conselho Regional de Engenharias e Agronomia - tornando-se referência em Engenharias no município.

\section{Proposta da pesquisa desenvolvida}

A Construção Civil, apesar de considerada uma das atividades mais importantes para o desenvolvimento social e econômico, é também a maior responsável por gerar resíduos sólidos no mundo. Não obstante, de acordo com Ceotto (2008 apud Silva et al.,2014) a construção civil consome $20 \%$ do total de energia produzida no país, gera cerca de $35 \%$ a $40 \%$ de todo lixo produzido nas atividades humanas, produz $400 \mathrm{~kg}$ de entulho por habitante, e ainda, durante a produção de cimento são gerados níveis de gás carbônico que equivalem à $9 \%$ de todo $\mathrm{CO} 2$ emitido no Brasil.

Para Aulicino (2008) a construção civil é a principal responsável pelas modificações na paisagem natural, uma vez que é fornecedora de toda a infraestrutura para 0 desenvolvimento das atividades humanas. Está fartamente comprovado que as fontes de energia usualmente utilizadas, além de outras atividades do ser humano, estão em conflito com os sistemas naturais da Terra. Pode-se identificar nas notícias diárias: encolhimento de florestas, erosão de solos, expansão de desertos, aumento constante dos níveis de dióxido de carbono $\left(\mathrm{CO}_{2}\right)$, queda de lençóis freáticos, aumento da 
temperatura, tempestades mais destrutivas, derretimento de geleiras, elevação do nível do mar, morte de recifes de coral e o início da maior extinção de plantas e animais desde o desaparecimento dos dinossauros, há 65 milhões de anos. Essas tendências, que assinalam uma relação cada vez mais conturbada entre a tecnologia e os ecossistemas da Terra, está causando prejuízos econômicos cada vez maiores e colocando em risco a vida no planeta.

Portanto, investir no uso de outros materiais provenientes dos descartes ou propor ainda diferentes formas de reduzir os resíduos, torna-se fundamental para a redução dos impactos ambientais causados. Pensando nisso, os alunos de Engenharia Civil EAD do polo Parauapebas/PA, executaram um estudo sobre a reutilização de escória de alto forno na dosagem do concreto.

A dosagem do concreto é o procedimento pelo qual se determina as proporções de cimento, água, agregados e aditivos que resultem em um concreto que atenda às características necessárias de qualidade previstas no projeto. Essas características variam de acordo com as limitações impostas pela obra e, também em relação ao estado do concreto, que no estado fresco, deve apresentar consistência adequada e coesão e, no endurecido, as características desejáveis são: resistência, durabilidade e outras de acordo com a finalidade do concreto, dentre elas temos: resistência a sulfatos, baixo calor de hidratação e alta resistência inicial (GIAMMUSSO,1992).

A escória de alto forno é um subproduto proveniente da fabricação de ferro gusa nos alto fornos (MASSUCATO, 2005), sendo composta principalmente de silicatos e sílicoaluminatos de cálcio amorfos, é obtida pela combinação das impurezas (canga) presentes nos minérios dos metais com fundentes apropriados e cinzas do carvão utilizado, sendo mais comumente o carvão vegetal. Estudos demonstram que a adição de escória de alto forno em cimentos contribui para melhora de diversas características no concreto fresco e endurecido, tais como: aumento da trabalhabilidade do concreto fresco, limitação do calor de hidratação, redução da expansão causada por reação álcaliagregado, redução da microfissuração, permeabilidade e porosidade. (MAGALHÃES, 2007).

A maior parte dos estudos sobre o uso de escória de alto forno diz respeito ao seu uso na substituição do cimento, cujos projetos que avaliam suas influências na substituição como agregado ainda são poucos e limitados. A indústria cimentícia é a maior consumidora de resíduos de alto forno na produção de cimento, entretanto, a produção do resíduo é alta e prejudicial ao meio ambiente. O surgimento de novas aplicações para esses resíduos pode reduzir custos de manutenção dos pátios de estocagem e plantas 
de beneficiamento, ou até mesmo a eliminação de alguns destes.

A siderúrgica SINOBRAS - Siderúrgica Norte Brasil S.A. - siderúrgica do Grupo instalada em Marabá (PA) - demonstra preocupação com as questões ambientais, tendo como um de seus valores o desenvolvimento sustentável, sua produção do aço é feita com $70 \%$ de sucata e $30 \%$ de ferro-gusa líquido (SINOBRAS, 2013), disponibilizou a escória de alto forno para o estudo, além de suas características físicas e químicas, demonstrando interesse na pesquisa, bem como colocou-se à disposição dos alunos para eventuais necessidades.

\section{Objetivos da pesquisa}

A referida pesquisa foi realizada com intuito de verificar a viabilidade e as vantagens da utilização de escória de alto-forno e de aciaria como constituintes de materiais utilizados na construção civil, por meio de ensaios mecânicos e análises físico-químicas das escórias de alto-forno e de aciaria aplicando-as como agregados no concreto. Além disso, buscou verificar também o comportamento da escória de alto-forno e de aciaria como aditivo em concreto convencional e ainda analisar possibilidades de aplicação das escórias na constituição de outros materiais utilizados na construção civil.

\section{Metodologia aplicada}

A definição do traço a ser utilizado seguiu o método ABCP - Associação Brasileira de Cimento Portland - conforme a NBR 12655 de dosagem experimental do concreto, a norma NBR 5738 (ABNT, 2004) para moldagem de corpos-de-prova. Os ensaios foram organizados cronologicamente, de modo que a execução dos traços e ensaios de resistência, de traços já curados, fossem executados nos mesmos dias. O intuito de criar um cronograma foi facilitar a execução da pesquisa, tendo em vista que alunos de EAD normalmente possuem horários de trabalho menos flexíveis, ou ainda residem em municípios distintos.

Definido o traço e a organização dos ensaios, procedeu-se os testes, as quantidades foram aferidas, vide Figura 1, conforme configuração mostrada a seguir:

Tabela 1 - Especificação do traço base. 


\begin{tabular}{|c|c|c|c|c|c|c|}
\hline Traço & $\begin{array}{c}\text { Cimento } \\
\left(\mathrm{kg} / \mathrm{m}^{3}\right)\end{array}$ & $\begin{array}{c}\text { Aditivo } \\
\left(\mathrm{ml} / \mathrm{m}^{3}\right)\end{array}$ & $\begin{array}{c}\text { Areia } \\
\left(\mathrm{kg} / \mathrm{m}^{3}\right)\end{array}$ & $\begin{array}{c}\text { Brita } \\
\left(\mathrm{kg} / \mathrm{m}^{3}\right)\end{array}$ & $\begin{array}{c}\text { Água } \\
\left(\mathrm{kg} / \mathrm{m}^{3}\right)\end{array}$ & $\begin{array}{c}\text { Slump } \\
(\mathrm{mm})\end{array}$ \\
\hline $1: 2: 3: 0,45$ & 433,33 & 1300 & 866,68 & 1299,99 & 195 & 80 \\
\hline
\end{tabular}

Fonte: Elaborada pelo autor.

Figura 1 - Alunos executando pesagem dos materiais.

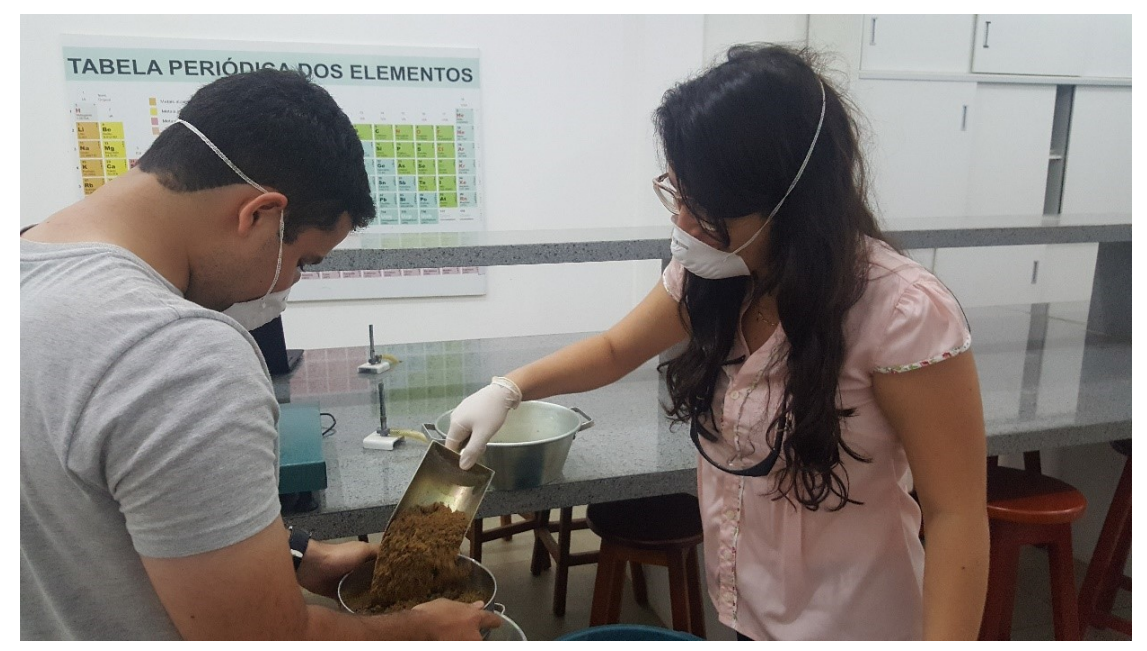

Fonte: Elaborada pelo autor.

Após a moldagem dos corpos de prova seguindo o traço base, como substituiu-se os agregados por escória granulada de alto forno (EAF), primeiramente o traço base foi executado com a escória substituindo o agregado miúdo (areia):

Tabela 2 - Especificação do Traço substituição Agregado Miúdo

\begin{tabular}{|c|c|c|c|c|c|c|}
\hline Traço & $\begin{array}{c}\text { Cimento } \\
\left(\mathrm{kg} / \mathrm{m}^{3}\right)\end{array}$ & $\begin{array}{c}\text { Aditivo } \\
\left(\mathrm{ml} / \mathrm{m}^{3}\right)\end{array}$ & $\begin{array}{c}\text { EAF } \\
\left(\mathrm{kg} / \mathrm{m}^{3}\right)\end{array}$ & $\begin{array}{c}\text { Brita } \\
\left(\mathrm{kg} / \mathrm{m}^{3}\right)\end{array}$ & $\begin{array}{c}\text { Água } \\
\left(\mathrm{kg} / \mathrm{m}^{3}\right)\end{array}$ & $\begin{array}{c}\text { Slump } \\
(\mathrm{mm})\end{array}$ \\
\hline $1: 2: 3: 0,45$ & 433,33 & 1300 & 866,68 & 1299,99 & 195 & 70 \\
\hline
\end{tabular}

Fonte: Elaborada pelo autor.

Posteriormente foi feito o mesmo com o agregado graúdo, substituindo-se os agregados graúdos (brita) por escória granulada de alto forno (EAF):

Tabela 3 - Especificação do Traço substituição Agregado Miúdo. 


\begin{tabular}{|c|c|c|c|c|c|c|}
\hline Traço & $\begin{array}{c}\text { Cimento } \\
\left(\mathrm{kg} / \mathrm{m}^{3}\right)\end{array}$ & $\begin{array}{c}\text { Aditivo } \\
\left(\mathrm{ml} / \mathrm{m}^{3}\right)\end{array}$ & $\begin{array}{c}\text { Areia } \\
\left(\mathrm{kg} / \mathrm{m}^{3}\right)\end{array}$ & $\begin{array}{c}\text { EAF } \\
\left(\mathrm{kg} / \mathrm{m}^{3}\right)\end{array}$ & $\begin{array}{c}\text { Água } \\
\left(\mathrm{kg} / \mathrm{m}^{3}\right)\end{array}$ & $\begin{array}{c}\text { Slump } \\
(\mathrm{mm})\end{array}$ \\
\hline $1: 2: 3: 0,45$ & 433,33 & 1300 & 866,68 & 1299,99 & 195 & 80 \\
\hline
\end{tabular}

Fonte: Elaborada pelo autor.

Os materiais foram misturados em masseira, conforme mostra Figura 2, para os ensaios foram moldados corpos-de-prova cilíndricos com $10 \mathrm{~cm}$ de diâmetro e $20 \mathrm{~cm}$ de altura $(10 \times 20 \mathrm{~cm})$, moldados em duas camadas.

Figura 2 - Aluno executando mistura do concreto em masseira.

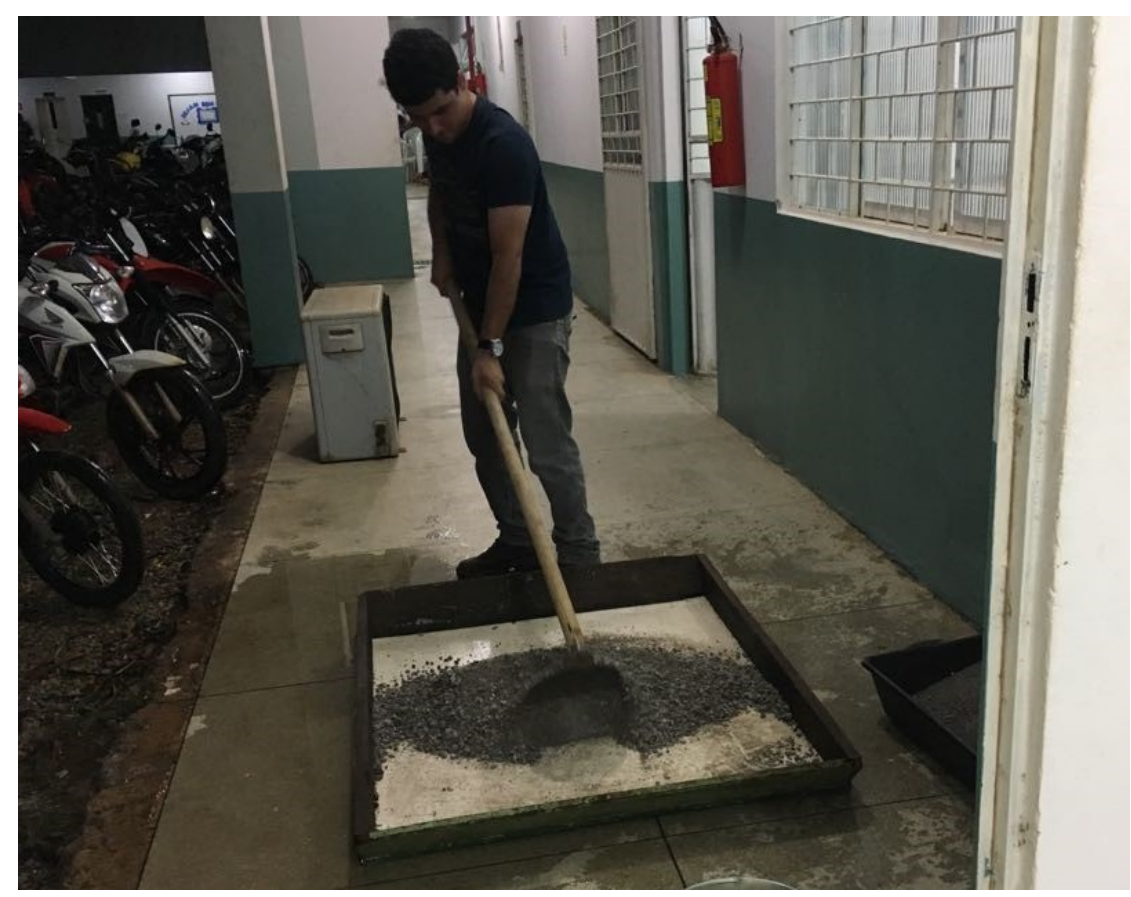

Fonte: Elaborada pelo autor.

O ensaio de abatimento, que visa verificar a trabalhabilidade dos concretos, foi executado em todos os traços conforme NBR NM 67 (ABNT, 1998).

Figura 3 - Aluno executando ensaio de abatimento do concreto - SlumpTest. 


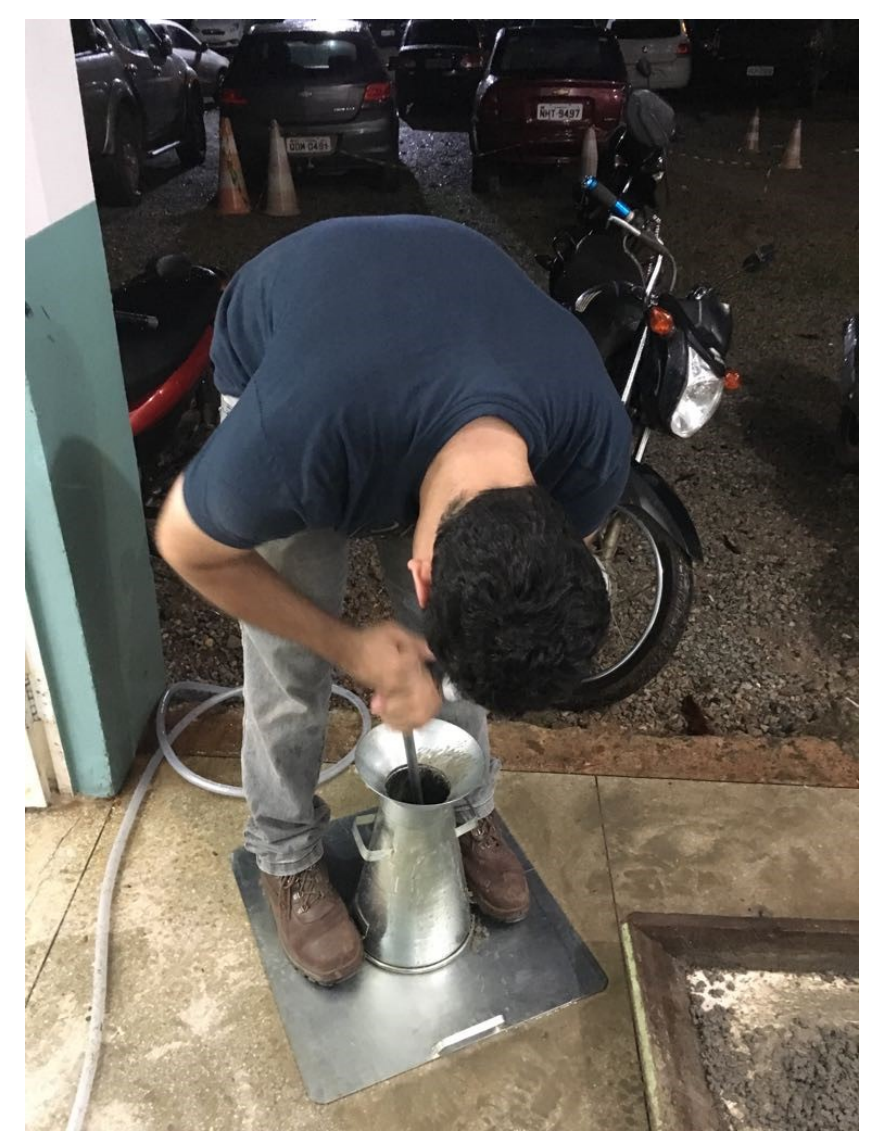

Fonte: Elaborada pelo autor.

O método de cura adotado é conhecido como "cura úmida", um processo que visa controlar a hidratação do concreto como garantia de que no processo de endurecimento, a água presente na pasta não seja perdida por meio de evaporação causada pelo calor de hidratação, podendo, desse modo, desencadear retração, o que acarreta no surgimento de fissuras que podem afetar o desempenho do concreto, sendo assim, os corpos de prova foram imersos completamente em água por um prazo de sete dias.

Os corpos de prova foram identificados conforme o traço aplicado, após a desmoldagem os corpos de prova permaneceram no laboratório, expostos à temperatura de em média $27^{\circ}$ e umidade relativa do ar de $89 \%$.

Os ensaios de resistência à compressão axial foram executados de acordo com os parâmetros da NBR 5739 (ABNT, 1994), vide Figura 5, e foram programados para serem realizados aos 7, 14 e 28 dias de idade, as rupturas foram iniciadas, e seguem em andamento enquanto este relato é elaborado, sendo programadas para uso de 4 corpos de prova em cada ensaio.

Figura 3 - Ensaio de compressão Axial. 


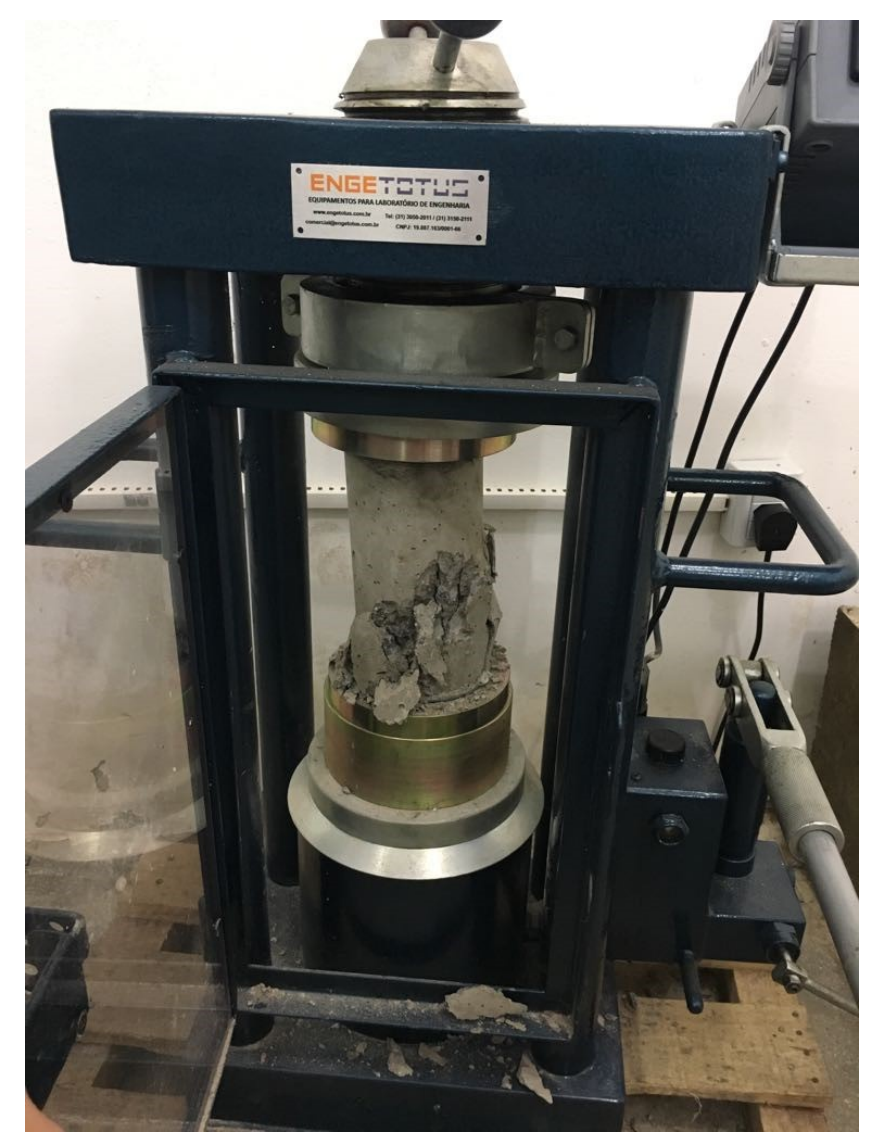

Fonte: Elaborada pelo autor.

Os resultados ainda não são conclusivos, tendo em vista que no momento da elaboração do presente artigo, os alunos estavam realizando os ensaios finais de dosagem, com previsão de finalização dos testes de resistência dentro de um mês, porém, os primeiros dados já demonstram que o uso da escória de alto forno agrega características positivas, tanto ao concreto fresco, quanto em seu estado endurecido.

\section{Conclusões}

Durante o período de orientação foi possível perceber que os alunos se mostraram muito mais interessados nas disciplinas relacionadas ao estudo. O contato com a prática da pesquisa fomentou no grupo a ânsia por mais conhecimento, que passou a ser construído a partir de uma iniciativa coletiva, o que deu fôlego à execução de outras pesquisas coerentes com a proposta já pensada. A pesquisa é fundamental não somente para ampliar conhecimento e propiciar novas habilidades, mas também incentiva a comunicação e trabalho em equipe, requisitos fundamentais para quem visa sucesso no mercado de trabalho.

A organização foi crucial para que a pesquisa fosse possível. Como já afirmado anteriormente, alunos de EAD tendem a possuir horários de trabalho menos flexíveis ou 
residência fora do município do polo presencial, dessa forma, organizar um cronograma para que os alunos possam realizar pesquisa sem a necessidade de estar constantemente no polo, possibilitou a realização de estudos que exigiram utilização das instalações do polo de apoio presencial, caso do referido estudo, tendo em vista que dosagem, moldagem e rompimento dos corpos de prova foram todos realizados no Polo de Parauapebas/PA.

Outro aspecto crucial para a realização do estudo foi a tutoria presencial do polo. Um dos fatores que influenciaram o interesse dos alunos pela pesquisa foi um circuito de palestras ministradas por alguns professores-tutores. Conversas e orientações durante os atendimentos tutoriais, também foram fecundas para se mostrar e discutir os resultados de pesquisas de outras universidades, estimular a participação em competições e congressos com o propósito de instigar a curiosidade e interesse dos alunos pela pesquisa científica. Após um dos atendimentos o grupo procurou a tutoria do polo na busca de orientação para o início do estudo.

Ao ser indagado sobre o motivo de estar realizando essa pesquisa científica, o aluno Mauro Felipe, integrante do grupo, fez a seguinte afirmação "Ao nos formarmos, todos da turma terão o mesmo diploma, que terá o mesmo valor no mercado de trabalho. $O$ que irá nos diferenciar um dos outros são as habilidades e conhecimentos extras que adquirimos ao longo do nosso percurso, a história que deixamos na Universidade e 0 nome que construímos". A fala do aluno reforça a concepção de que a pesquisa científica não forma apenas acadêmicos, pois ela também permite que futuros profissionais tenham a capacidade de criar, indagar e problematizar antigos conceitos, tornando-os aptos a enfrentar, com sucesso, o competitivo mercado de trabalho.

\section{REFERÊNCIAS}

ABNT - ASSOCIAÇÃO BRASILEIRA DE NORMAS TÉCNICAS. NBR 5738: Concreto Procedimento para moldagem e cura de corpos-de-prova. Rio de Janeiro: ABNT, 2004.

ABNT - ASSOCIAÇÃO BRASILEIRA DE NORMAS TÉCNICAS. NBR 5739: Concreto: ensaio de compressão de corpos-de-prova cilíndricos de concreto - Método de ensaio. Rio de Janeiro: ABNT, 1994.

ABNT - ASSOCIAÇÃO BRASILEIRA DE NORMAS TÉCNICAS. NBR 12655: Concreto de Cimento Portland - Preparo, controle e recebimento - Procedimento. Rio de Janeiro: ABNT, 2006. 
ABNT - ASSOCIAÇÃO BRASILEIRA DE NORMAS TÉCNICAS. NBR NM 67: Concreto - Determinação da consistência pelo abatimento do tronco de cone. Rio de Janeiro: ABNT, 1998.

AULICINO, P.; Análise de Métodos de Avaliação de Sustentabilidade do Ambiente Construído: o Caso dos Conjuntos Habitacionais. Dissertação de Mestrado. Escola Politécnica da Universidade de São Paulo - Departamento de Engenharia Civil. São Paulo, 2008.

MAGALHÃES, A.G, Caracterização e análise macro e microestrutural de concretos fabricados com cimentos contendo escórias de alto-forno. Tese de Doutorado. Universidade Federal de Minas Gerais - Curso de Pós-Graduação em Engenharia de Estruturas. Belo Horizonte, 2007.

MASSUCATO, C.J., Utilização de escória de alto-forno à carvão vegetal como adição no concreto. Dissertação de Mestrado. Universidade Estadual de Campinas Faculdade de Engenharia Civil, Arquitetura e Urbanismo. Campinas, 2005.

GIAMMUSSO, S. E. Manual do Concreto. São Paulo, Ed. Pini, 1992.

SILVA, A. S. et al., Gestão dos resíduos sólidos gerado pelo setor da construção civil (construtoras) em Aracaju. Cadernos de Graduação - Ciências Exatas e Tecnológicas Unit, v. 2, n.1, p. 137-144. Aracaju, 2014.

SINOBRAS. Relatório de Sustentabilidade. Marabá, 2013. 